\title{
Crescimento inicial de plantas Euterpe edulis Mart. em diferentes condições de luz, água e nutrientes
}

\author{
Initial growth of seedlings of Euterpe edulis Mart. under different \\ conditions of light, water and mineral nutrients
}

\author{
Marilda Neuburger ${ }^{1}$, Thaysi Ventura de Souza ${ }^{2}$ \& Maria Terezinha Silveira Paulilo ${ }^{3}$
}

\begin{abstract}
Resumo
A introdução e manejo de plântulas de Euterpe edulis Mart. em florestas tem sido uma alternativa encontrada para não levar a espécie à extinção devido ao extrativismo desenfreado. O objetivo deste estudo é ampliar o conhecimento das exigências ecológicas das plântulas desta espécie, visando auxiliar sua conservação in situ. Frutos despolpados da espécie germinaram em casa de vegetação e as plântulas, ainda com os vestigios da semente ligados ao eixo embrionário, foram separadas em seis lotes. Cada lote recebeu os seguintes tratamentos: $2 \%$ de luminosidade, $50 \%$ de luminosidade, sem nutrição mineral, com nutrição mineral, irrigação a cada dois dias e irrigação a cada sete dias. Observou-se que o tempo de esgotamento das reservas das sementes não pareceu ser influenciado pela intensidade de luz e fertilidade do solo, como também o peso da matéria seca, área foliar e número de folhas das plântulas, sugerindo que o crescimento da plântula parece ser independente da intensidade de luz e fertilidade do solo enquanto há reservas na semente. Sob regime de menor disponibilidade de água, as plântulas apresentaram aumento no teor de prolina da folha, indicando que a espécie apresenta regulação osmótica As plântulas apresentaram inibição do crescimento a $2 \%$ de luz solar, indicando que o nível de luz solar que chega ao interior da floresta fechada pode ser limitante para o crescimento de plântulas desta espécie.

Palavras-chave: água, Arecaceae, luz, nutrientes minerais, palmiteiro, plântula.
\end{abstract}

\begin{abstract}
The introduction and management of Euterpe edulis seedlings in forests is an alternative that has been found to prevent the species' extinction. The aim of this study is to increase our knowledge of the ecological demands of seedlings of this species in order to contribute to in situ conservation. Fruits of Euterpe edulis without pulp were germinated in the greenhouse, in vermiculite moistened with water. The seedlings obtained, still with some seed reserves attached to the embryonic axis, were separated in six groups. Each received the following treatment: $2 \%$ sunlight, $50 \%$ sunlight, without mineral nutrition, with mineral nutrition, irrigation every other day and irrigation every seven days. It was observed that the time of seed-reserve depletion did not seem to be influenced by light intensity or soil fertility, nor did dry mass, leaf area and number of leaves, which suggests that seedling growth is independent of these environmental factors while the seed reserves are present. Under decreasing water, seedlings showed an increase in proline content, indicating a mechanism of osmotic regulation. The plants showed growth inhibition under $2 \%$ sunlight. This result indicates that the level of light intensity that reaches the interior of a closed forest can limit seedling growth.

Key words: water, Arecaceae, light, mineral nutrients, palmiteiro, seedling.
\end{abstract}

\section{Introdução}

O palmiteiro (Euterpe edulis Mart.), espécie climácica da floresta ombrófila densa (Conte et al. 2000), é de grande valor econômico, porém não se adapta facilmente ao monocultivo devido às suas exigências ecológicas (Clement 2000). A introdução e manejo do palmiteiro em florestas naturais ou plantadas tem sido uma alternativa encontrada para não levar a espécie à extinção devido ao extrativismo desenfreado (Reis et al. 2000). Tanto para a introdução quanto para o manejo de uma espécie, há a necessidade do conhecimento de suas exigências ecológicas,

${ }^{1}$ Mestre em Biologia Vegetal. Programa de Pós-Graduação em Biologia Vegetal, UFSC.

${ }^{2}$ Mestranda em Biologia Vegetal. Programa de Pós-Graduação em Biologia Vegetal, UFSC.

${ }^{3}$ Autor para correspondência: Universidade Federal de Santa Catarina, Centro de Ciências Biológicas, Depto. Botânica, Programa de Pós-Graduação em Biologia Vegetal, Campus Universitário, 88040-900, Florianópolis, SC, Brasil. paulilo@ccb.ufsc.br 
principalmente na fase de estabelecimento de plântulas, uma das fases do ciclo de vida dos vegetais mais vulneráveis ao ambiente (Haig \& Westoby 1991). O ambiente florestal não é homogêneo em relação aos recursos luminosos, hídricos e minerais, principalmente quanto ao nitrogênio e fósforo (Chapin et al. 1987), o que poderia afetar a colonização de plântulas num ou noutro local da floresta. Algumas características apresentadas pelas espécies, como o tempo de duração das reservas da semente (Houter \& Steege 2000) e a plasticidade das plântulas em maximizar a captação dos recursos (Fetene \& Feleke 2001) podem favorecer a colonização numa gama maior de ambientes florestais, aumentando sua probabilidade de regeneração.

Estudos anteriores com Euterpe edulis verificaram aspectos relacionados ao tempo de degradação de reservas (Andrade et al. 1996; Venturi \& Paulilo 1998), à influência da variação da adubação (Venturi \& Paulilo 1998) e da intensidade de luz (Nakazono et al. 2001) no crescimento de plantas. O objetivo deste trabalho, entretanto, é verificar a influência da luz e adubação na velocidade de esgotamento das reservas, a interação entre luz e adubação no crescimento inicial de plantas, bem como as respostas de crescimento à variação da disponibilidade hídrica.

\section{Material e Métodos}

Para realização deste estudo foram utilizados frutos oriundos de indivíduos de Euterpe edulis Mart., popularmente conhecido por palmiteiro ou jussara, localizados no Parque Botânico do Morro do Baú - Ilhota/SC (experimentos de esgotamento das reservas e de efeito de luz e nutrientes) ou no município de Florianópolis (experimento de disponibilidade hídrica). Logo após a coleta, os mesmo foram despolpados.

Para obtenção de plântulas, frutos despolpados foram colocados para germinar em casa de vegetação, utilizando-se caixas de madeira de $40 \mathrm{~cm}$ de comprimento, $30 \mathrm{~cm}$ de largura e $6 \mathrm{~cm}$ de altura, contendo vermiculita umedecida com água.

Visando a verificação do tempo de esgotamento das reservas foram separados visualmente 50 frutos despolpados de tamanho semelhante, as quais foram separadas em embrião e restante do fruto e as partes levadas para estufa a $80^{\circ} \mathrm{C}$ até peso constante. Para determinação do peso foi utilizada balança analítica com três casas decimais.

Entre 15 e 135 dias após a semeadura, a cada 15 dias, 15 plântulas de tamanho semelhante foram coletadas e separadas em eixo embrionário e restante da semente, sendo o peso da matéria seca avaliado para ambas as partes, utilizando-se a mesmo procedimento acima.
Plantas com 135 dias, em número de 252, foram retiradas das caixas de madeira com vermiculita e transplantadas para sacos plásticos pretos, furados na base, de 1L de volume, contendo areia, barro e vermiculite na proporção 2:1:2. As plântulas foram separadas em quatro lotes, 63 plantas por lote, cada lote recebendo um dos seguintes tratamentos: Tratamento 1: 2\% luz, com adubação; Tratamento 2: $2 \%$ luz, sem adubação; Tratamento 3: 50\% luz, com adubação; Tratamento 4: 50\% luz, sem adubação. Cada tratamento constou de três unidades experimentais, cada unidade com 21 plantas. Nos tratamentos com adubação, as plantas foram irrigadas mensalmente com $50 \mathrm{~mL}$ de solução de NPK, na concentração de $1,4 \mathrm{mg} \mathrm{mL}^{-1}$. A redução de luz solar foi obtida com por tela de sombreamento de $50 \%$ ou $98 \%$ de redução de luz. A cada 30 dias após o início do experimento, foram coletadas nove plantas por tratamento para determinação do peso da matéria seca de órgãos vegetais, da área foliar e do número de folhas, e, em seguida, procedimento da análise de crescimento. Estes experimentos foram conduzidos por dois anos em área aberta do Departamento de Botânica da Universidade Federal de Santa Catarina.

O crescimento de Euterpe edulis sob diferentes disponibilidades de água foi determinado para indivíduos obtidos a partir da germinação de sementes, como descrita anteriormente. Para tanto foram escolhidas 78 plantas com a primeira folha fotossintetizante em início de expansão, seis para a análise de prolina e 72 para as demais medidas, as quais foram transplantadas para sacos plásticos pretos, furados na base, de 1,5 L de volume, contendo terra de mata e compostagem termofílica na proporção de 1:1 e colocadas sob tela de sombreamento de $50 \%$ de redução de luz. Metade das plântulas foi irrigada até percolação, a cada dois dias, e a outra metade recebeu irrigação até percolação a cada sete dias. As plantas foram divididas em três unidades experimentais com 12 plantas cada. Após 85 e 170 dias, nove plântulas de cada tratamento hídrico foram coletadas, medindo-se o teor de prolina da folha, o peso da matéria seca, a área foliar e procedendo-se à análise de crescimento.

A umidade do substrato em capacidade de campo foi calculada subtraindo-se a massa de sete amostras de 1,5L de substrato irrigado até percolação da massa de peso da matéria seca (MS) destas amostras após secagem em estufa até massa constante, sendo obtido o valor de $0,29 \mathrm{gH}_{2} 0 / \mathrm{gMS}$, que equivale a $100 \%$ da água que o substrato pode reter. A umidade do solo no tratamento de deficiência hídrica foi obtida pesando-se o substrato após 30 dias sem irrigação. 
Foram calculadas as taxas de crescimento relativo em termos de peso de matéria seca (TCR) e razão de área foliar (RAF), segundo Hunt (1982), sendo TCR $=\ln \mathrm{m}_{2}-\ln \mathrm{m}_{1} / \mathrm{t}_{2}-\mathrm{t}_{1}$ e RAF $=\left(\mathrm{a}_{1} / \mathrm{m}_{1}+\right.$ $\left.\mathrm{a}_{2} / \mathrm{m}_{2}\right) / 2$. Onde: $\mathrm{m}_{2}=$ peso da matéria seca da planta na coleta final; $\mathrm{m}_{1}=$ peso da matéria seca da planta na coleta inicial; $\mathrm{t}_{1}-\mathrm{t}_{2}=$ intervalo de tempo entre as coletas inicial e final; $\mathrm{a}_{1}=$ área foliar da planta na coleta inicial; $\mathrm{a}_{2}=$ área foliar da planta na coleta final.

A área foliar foi obtida através da comparação do peso do contorno de folhas desenhadas em papel com o peso de áreas conhecidas do mesmo papel. O peso da matéria seca de raiz, caule e folhas foi obtido colocando-se as partes vegetais para secar em estufa a $80^{\circ} \mathrm{C}$ até peso constante, sendo pesadas após este período. A altura da planta foi medida utilizando-se régua plástica, medindo-se desde a região de transição entre raiz e caule até a base da folha mais nova.

A determinação dos níveis de prolina foi feita segundo método de Bokhari \& Trent (1985). Três folhas recém expandidas de três plântulas por tratamento foram picotadas, misturadas e separadas em três amostras de $500 \mathrm{mg}$ de matéria fresca. Cada amostra de folhas foi macerada em $10 \mathrm{~mL}$ de ácido sulfosalicílico (solução aquosa a 3\%). Os macerados obtidos foram centrifugados a $3000 \mathrm{~g}$ e alíquotas de $2 \mathrm{~mL}$ do sobrenadante (três alíquotas por amostra) foram retiradas e colocadas em tubos de ensaio (uma alíquota por tubo), juntamente com $2 \mathrm{~mL}$ do reagente nihidrina ácida $(1,25 \mathrm{~g}$ de nihidrina a 20 $\mathrm{mL}$ de ácido acético glacial e a $20 \mathrm{~mL}$ de ácido acético fosfórico a $6 \mathrm{M} \mathrm{em}$ banho-maria a $70^{\circ} \mathrm{C}$ ) e $2 \mathrm{~mL}$ de ácido acético glacial. Os tubos com a solução resultante foram aquecidos em banho-maria a $100^{\circ} \mathrm{C}$ por $1 \mathrm{~h}$ e a reação interrompida colocando-se os tubos em banho de gelo. Foram, então, acrescentados a cada tubo $4 \mathrm{ml}$ de tolueno, agitando-se, posteriormente, para mistura dos líquidos. Após repouso para separação das fases, a fração tolueno foi retirada e sua absorbância medida a $520 \mathrm{~nm}$, em espectofotômetro. A absorbância obtida foi comparada com a absorbância de soluções-padrão de prolina em concentrações de $0-2-4-6-8-16 \mu \mathrm{gL} \mathrm{m}^{-1}$, sendo utilizadas três repetições por concentração.

O experimento para determinação do efeito de luz e nutrientes e o de disponibilidade hídrica foram arranjados em delineamento completamente casualizado e, no primeiro caso, em fatorial de $2 \times 2$ ( 2 luminosidades x 2 condições de nutrição do substrato). Cada experimento constou de três unidades amostrais. A cada coleta, de cada experimento, foram retiradas três plantas por unidade amostral, perfazendo nove plantas por coleta. Apenas para determinação do teor de prolina foram utilizadas três plantas por tratamento, uma por unidade amostral. Os dados foram inicialmente avaliados quanto à homogeneidade de variância de acordo com o teste de Levene, e quando necessário, houve transformação dos dados para atender os pressupostos do teste estatístico paramétricos. Os dados foram avaliados em nível de $5 \%(\mathrm{p}<0,05)$ de probabilidade de erro, utilizando-se análise de variância multifatorial (experimento 2), com comparação de médias pelo teste Tukey, ou teste $t$ de Student, no caso do experimento 3 (Banzatto \& Kronka 1989). Utilizou-se o programa estatístico Statistica, versão 6.0 .

\section{Resultados \\ Verificação do tempo de esgotamento das reservas}

O peso da matéria seca do eixo embrionário e dos restos da semente pelo período de 255 dias após a semeadura (DAS) das sementes, mantidas a $2 \%$ e $50 \%$ de luminosidade, pode ser observado na Figura 1. Observa-se que a maior parte das reservas das sementes já foi consumida até 135 DAS, época em que as plantas apresentavam a primeira folha fotossintetizante ainda enrolada. Até esta fase, as sementes perderam cerca de $70 \%$ de sua matéria seca original. Assim, a maior parte das reservas foi gasta antes da planta apresentar a primeira folha fotossintetizante completamente expandida. Os restantes $33 \%$ das reservas foram gastos até o dia 255 DAS, quando as plantas já apresentavam duas folhas fotossintetizantes expandidas. Este gasto das reservas restantes deu-se de maneira semelhante, independentemente do tratamento de luz ou nutricional a que as plantas foram submetidas após 135 DAS. Observa-se que a velocidade de perda de reservas não foi sempre a mesma. Houve uma fase mais lenta entre 15 e 105 DAS onde a perda da matéria seca foi cerca de 2,0 $\mathrm{mg} \mathrm{dia}^{-1}$, uma fase mais rápida entre os dias 105 e 165 DAS, com uma perda da matéria seca de cerca de 5,0 $\mathrm{mg} \mathrm{dia}^{-1}$ e novamente uma fase mais lenta, dos 165 até o término das reservas, aos 255 DAS, onde a perda da matéria seca foi cerca de $0,7 \mathrm{mg} \mathrm{dia}^{-1}$.

\section{Resposta da planta em diferentes intensidades de luz e disponibilidade de nutrientes \\ O peso da matéria seca total das plantas (Fig. 2)} não foi afetado pelos tratamentos de luz e nutricional até 195 dias após a semeadura. A partir de 405 DAP, verifica-se que os nutrientes têm maior importância 

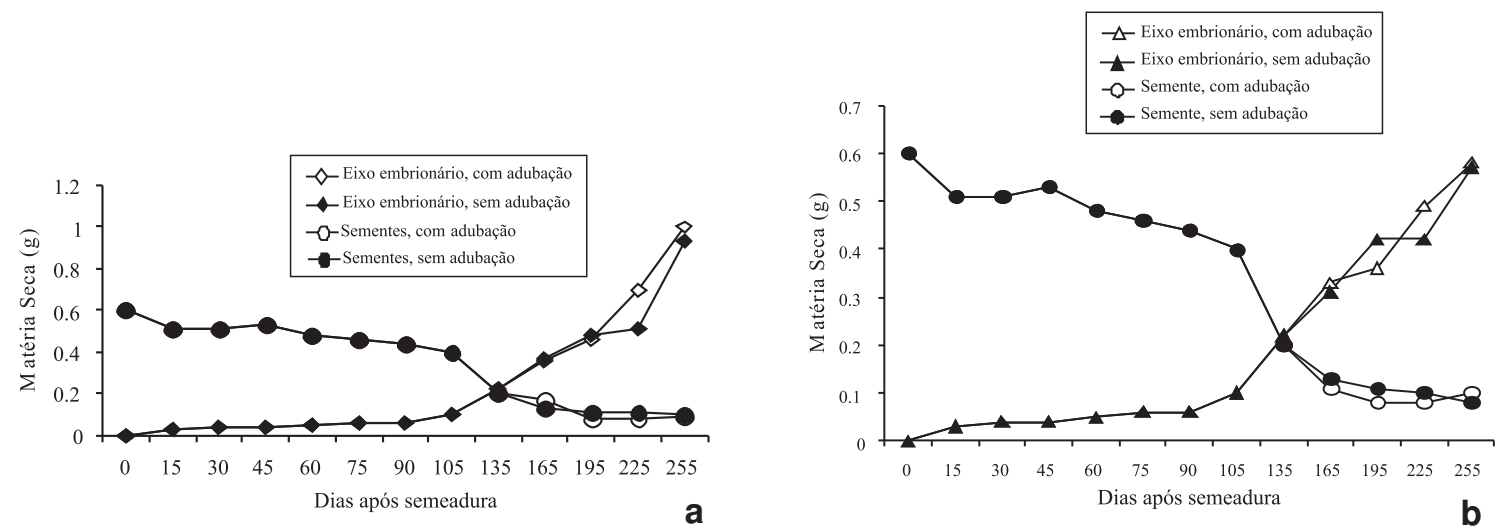

Figura 1 - Médias do peso de matéria seca (g) do eixo embrionário e dos restos da semente de plântulas de Euterpe edulis submetidas a diferentes adubações do substrato - a. $50 \%$ de intensidade de luz; b. $2 \%$ de intensidade de luz.

Figure 1 - Embryonic axis and remains of seed dry matter weight ( $\mathrm{g}$ ) of plants of Euterpe edulis submitted to different substrate fertilization - a. $50 \%$ of light intensity; b. $2 \%$ of light intensity.

no crescimento em peso de matéria seca que a luz, sendo que plantas crescidas a $2 \%$ de luz com nutriente apresentam maior peso de matéria seca que plantas a $50 \%$ de luz sem nutrientes. As plantas com mais luz e mais nutrientes apresentaram a partir de 405 DAS significativo aumento do peso de matéria seca em relação aos demais tratamentos, mostrando o teste F para interação entre os fatores luz e nutrição, interação significativa entre estes dois fatores a partir desta data $(\leq 0,05)$.

O resultado verificado para peso de matéria seca total a partir de 405 DAP não foi devido ao peso da matéria seca da raiz (Fig. 3), mas sim da parte aérea (Fig. 4).

Em relação à área foliar total (Fig. 5), o efeito dos tratamentos é mais marcante a partir dos 405 DAP, verificando-se que a área foliar total de plantas com nutrientes é maior independentemente da intensidade luminosa aplicada. A área foliar de plantas em intensidade de luz mais alta e sem nutrientes foi a mais baixa entre os tratamentos a partir dos 405 DAP. Já o número de folhas (Fig. 6) foi semelhante para os tratamentos até 405 DAP, à exceção das plantas sob maior intensidade de luz e sem nutrientes. Os dados indicam que a ausência de nutrientes prejudicou a área foliar e a emergência de folhas, apontando que a nutrição é um fator mais limitante que intensidade de luz para o crescimento inicial de plantas de palmiteiro. A partir de 405 DAP, mesmo tendo ocorrido anteriormente o aumento e área foliar com adubação, a área foliar começa a diminuir em todos os tratamentos devido à queda de folhas, observada neste período. A altura do caule (Fig. 7) também foi limitada em alta intensidade de luz e na ausência de nutrientes.

A taxa média de crescimento relativo (TCR) das plantas a $50 \%$ de luz com adição de nutrientes manteve valores mais altos que plantas sob os demais tratamentos durante quase todo o tempo de experimentação (Tab. 1) A razão de área foliar foi maior em plantas sob menor intensidade de luz, não havendo influências da nutrição das plantas (Tab. 2).

\section{Resposta da planta a diferentes disponibilidades de água}

As plantas não irrigadas por 14 e 30 dias não apresentaram diferença no crescimento em massa de peso da matéria seca, área foliar, número de folhas e comprimento do caule em relação às irrigadas (controle) e nem no teor de prolina (Tab. 3). O teor de água do substrato após 30 dias sem irrigação foi de $0,039 \mathrm{gH}_{2} 0 / \mathrm{gMS}$, equivalendo a $13,5 \%$ da capacidade de campo.

\section{Discussão}

\section{Verificação do tempo de esgotamento das reservas}

As reservas da semente de Euterpe edulis se esgotaram quando as plântulas apresentavam a segunda folha palmada bem expandida, independentemente da intensidade de luz ou adubação aplicada. Cerca de $70 \%$ das reservas sendo gastas até a plântula apresentar o início do desenvolvimento da primeira 


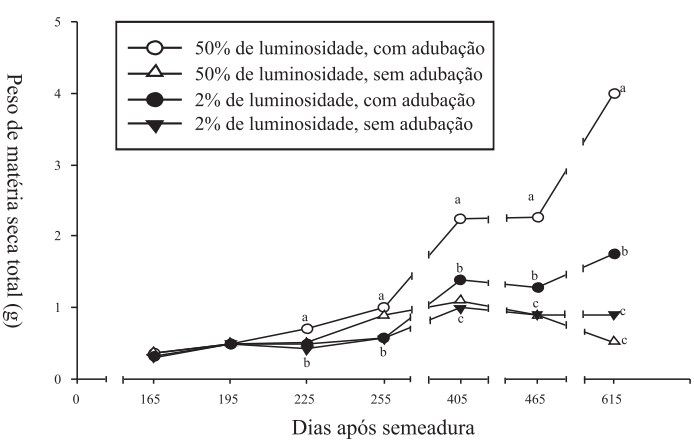

Figura 2 - Médias de peso de matéria seca (g) de plantas de Euterpe edulis submetidas a diferentes condições de luminosidade e adubação do substrato.

Figure 2 - Dry matter weight (g) of plants of Euterpe edulis submitted to different conditions of light intensity and substrate fertilization.

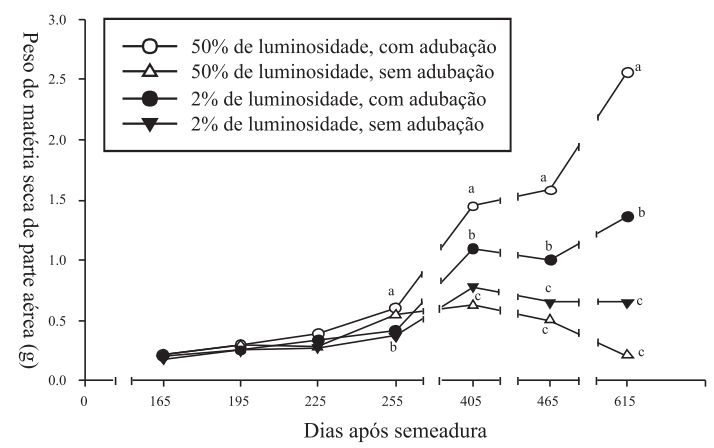

Figura 4 - Médias de peso de matéria seca $(\mathrm{g})$ de parte aérea de plantas de Euterpe edulis submetidas a diferentes condições de luminosidade e adubação do substrato.

Figure 4 - Shoot dry matter weight (g) of plants of Euterpe edulis submitted to different conditions of light intensity and substrate fertilization.

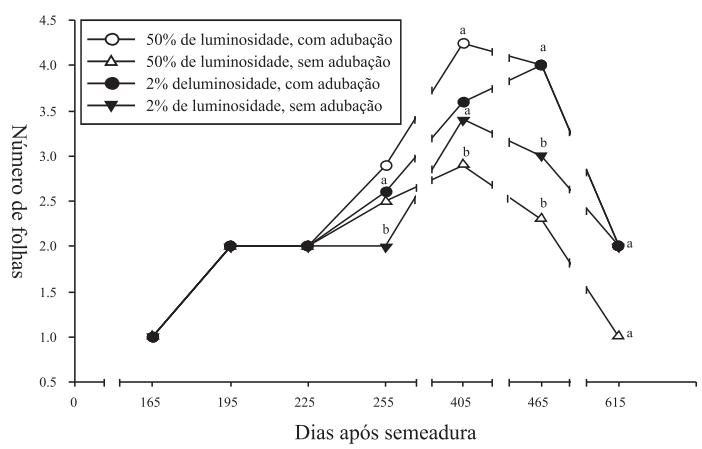

Figura 6 - Número de folhas de plantas de Euterpe edulis submetidas a diferentes condições de luminosidade e adubação do substrato.

Figure 6-Number of leaves of plants of Euterpe edulis submitted to different conditions of light intensity and substrate fertilization.

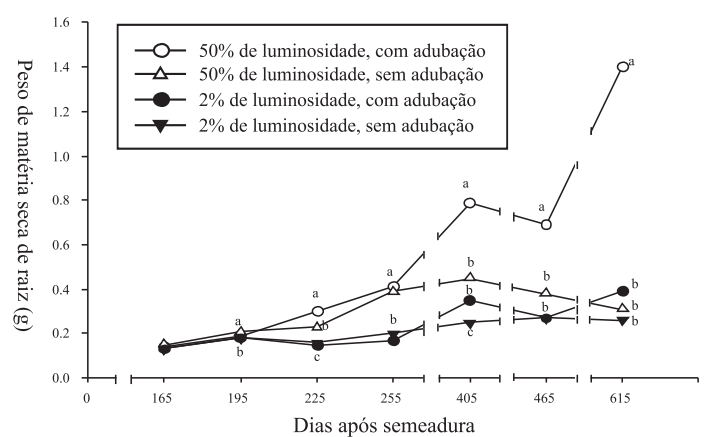

Figura 3 - Médias de peso de matéria seca (g) de raiz de plantas de Euterpe edulis submetidas a diferentes condições de luminosidade e adubação do substrato.

Figure 3 - Root dry matter weight (g) of plants of Euterpe edulis submitted to different conditions of light intensity and substrate fertilization.

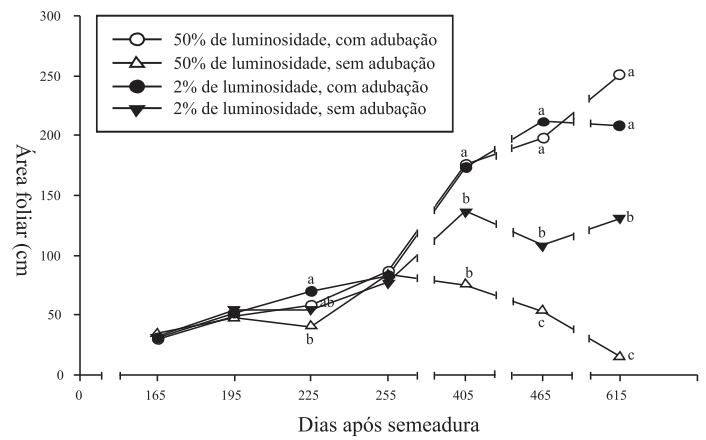

Figura 5 - Área foliar $\left(\mathrm{cm}^{2}\right)$ de plantas de Euterpe edulis submetidas a diferentes condições de luminosidade e adubação do substrato.

Figure 5 - Leaf area $\left(\mathrm{cm}^{2}\right)$ of plants of Euterpe edulis submitted to different conditions of light intensity and substrate fertilization.

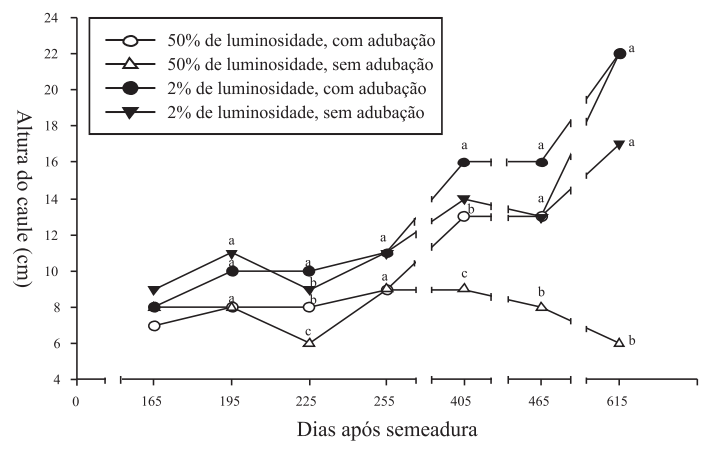

Figura 7 - Altura do caule (cm) de plantas de Euterpe edulis submetidas a diferentes condições de luminosidade e adubação do substrato.

Figure 7 - Stem weight of plants of Euterpe edulis submitted to different conditions of light intensity and substrate fertilization. 
Tabela 1 - Taxa de crescimento relativo (TCR) de plantas de Euterpe edulis submetidas a diferentes condições de luminosidade e adubação do substrato.

Table 1 - Relative growth rate (TCR) of plants of Euterpe edulis submitted to different conditions of light intensity and substrate fertilization

\begin{tabular}{lcccc}
\hline \multicolumn{5}{c}{ TCR $\left(\mathrm{mg} \mathrm{d}^{-1}\right)$} \\
\hline Intervalo de tempo (DAP) & $\mathrm{CN}$ & $\mathrm{SN}$ & $\mathrm{CN}$ de luz & $\mathrm{SN}$ \\
$195-165$ & $0,009 \mathrm{a}$ & $0,010 \mathrm{a}$ & $0,011 \mathrm{a}$ & $0,009 \mathrm{a}$ \\
$225-195$ & $0,001 \mathrm{~b}$ & $0,001 \mathrm{~b}$ & $0,011 \mathrm{a}$ & $0,002 \mathrm{~b}$ \\
$255-225$ & $0,004 \mathrm{~b}$ & $0,003 \mathrm{~b}$ & $0,014 \mathrm{a}$ & $0,016 \mathrm{a}$ \\
$405-225$ & $0,007 \mathrm{a}$ & $0,003 \mathrm{~b}$ & $0,006 \mathrm{a}$ & $0,001 \mathrm{c}$ \\
$465-405$ & $(-)$ & $(-)$ & $0,002 \mathrm{a}$ & $(-)$ \\
$615-465$ & $0,004 \mathrm{a}$ & 0,0 & $0,006 \mathrm{a}$ & $(-)$ \\
\hline
\end{tabular}

$\mathrm{DAP}=$ Dias após a semeadura, $(-)$ taxa negativa de crescimento relativo e $\mathrm{CN}=$ com adição de nutrientes, $\mathrm{SN}=$ sem adição de nutrientes. Médias seguidas de mesma letra na linha não diferem entre si pelo teste de Tukey $(\mathrm{p}<0,05)$.

$\mathrm{DAP}=$ Days after sowing, (-) negative relative growth rate and $\mathrm{CN}=$ with addition of nutrients, $\mathrm{SN}=$ without addition of nutrients. Means followed by same letters in line are not significantly different, according to the Tukey's test $(\mathrm{p}<0.05)$.

Tabela 2 - Razão de área foliar (RAF) de plantas de Euterpe edulis submetidas a diferentes condições de luminosidade e adubação do substrato.

Table 2 - Leaf area rate (RAF) of plants of Euterpe edulis submitted to different conditions of light intensity and substrate fertilization.

\begin{tabular}{lcccc}
\hline \multicolumn{5}{c}{ RAF $\left(\mathrm{cm}^{-2} \mathrm{mg}^{-1}\right)$} \\
\hline Intervalo de tempo (DAP) & $\mathrm{CN}$ & $\mathrm{SN}$ & $\mathrm{CN} \%$ de luz & $\mathrm{SN}$ \\
$195-165$ & $0,119 \mathrm{a}$ & $0,117 \mathrm{a}$ & $0,96 \mathrm{~b}$ & $0,97 \mathrm{~b}$ \\
$225-195$ & $0,147 \mathrm{a}$ & $0,106 \mathrm{~b}$ & $0,96 \mathrm{c}$ & $0,907 \mathrm{c}$ \\
$255-225$ & $0,143 \mathrm{a}$ & $0,109 \mathrm{~b}$ & $0,84 \mathrm{c}$ & $0,84 \mathrm{c}$ \\
$405-225$ & $0,132 \mathrm{a}$ & $0,107 \mathrm{~b}$ & $0,82 \mathrm{c}$ & $0,81 \mathrm{c}$ \\
$465-405$ & $0,146 \mathrm{a}$ & $0,82 \mathrm{~b}$ & $0,83 \mathrm{~b}$ & $0,65 \mathrm{~b}$ \\
$615-465$ & $0,100 \mathrm{a}$ & $0,112 \mathrm{a}$ & $0,70 \mathrm{~b}$ & $0,46 \mathrm{c}$ \\
\hline
\end{tabular}

$\mathrm{DAP}=$ Dias após a semeadura, $\mathrm{CN}=$ com adição de nutrientes, $\mathrm{SN}=$ sem adição de nutrientes. Médias seguidas de mesma letra na linha não diferem entre si pelo teste de Tukey $(\mathrm{p}<0,05)$.

DAP=Days after sowing, (-) negative relative growth rate and $\mathrm{CN}=$ with addition of nutrients, $\mathrm{SN}=$ without addition of nutrients. Means followed by same letters in line are not significantly different, according to the Tukey's test $(\mathrm{p}<0.05)$

Tabela 3 - Médias de peso de matéria seca, área foliar, número de folhas e teor de prolina em plantas de Euterpe edulis, submetidas à baixa irrigação.

Table 3 - Dry weight matter, leaf area, leaf number and proline content in plants of Euterpe edulis submitted to low water.

\begin{tabular}{llllllll}
\hline Tratamentos & Raiz $(\mathrm{mg})$ & Folha $(\mathrm{mg})$ & Parte Aérea $(\mathrm{mg})$ & Total $(\mathrm{mg})$ & Área Foliar $\left(\mathrm{cm}^{2}\right)$ & $\mathrm{N}^{\circ}$ Folha & $\mu \mathrm{g}$ prolina $\mathrm{mg}^{-1}$ \\
\hline Controle & $329 \mathrm{a}$ & $479 \mathrm{~b}$ & $781 \mathrm{a}$ & $1110 \mathrm{a}$ & $126,85 \mathrm{a}$ & $3 \mathrm{a}$ & $0,23 \mathrm{a}$ \\
$\begin{array}{l}14 \text { dias sem } \\
\text { irrigação }\end{array}$ & $392 \mathrm{a}$ & $517 \mathrm{a}$ & $821 \mathrm{a}$ & $1213 \mathrm{a}$ & $135,96 \mathrm{a}$ & $3 \mathrm{a}$ & $0,22 \mathrm{a}$ \\
$\begin{array}{l}\text { Controle } \\
\text { 30 dias sem }\end{array}$ & 705A & $1058 \mathrm{~A}$ & $1841 \mathrm{~A}$ & $2682 \mathrm{~A}$ & $267 \mathrm{~A}$ & $5 \mathrm{~A}$ & $0,23 \mathrm{~A}$ \\
irrigação & & $1279 \mathrm{~A}$ & $2070 \mathrm{~A}$ & $2991 \mathrm{~A}$ & $275 \mathrm{~A}$ & $5 \mathrm{~A}$ & $0,26 \mathrm{~A}$ \\
\hline
\end{tabular}

As letras minúsculas comparam controle e 14 dias sem irrigação e as maiúsculas, controle e 30 dias sem irrigação. Médias seguidas de mesma não diferem entre si pelo teste de $t(\mathrm{p}<0,05)$.

The small letters compare control and plants without irrigation during 14 days and the capital letters compare control and plants without irrigation during 30 days. Means followed by same letters are not significantly different, according to the $t$ test $(\mathrm{p}<0.05)$. 
folha palmada, os $30 \%$ restantes foram gastos entre o estádio de desenvolvimento anterior e o estádio em que a planta jovem apresentou a segunda folha palmada expandida, resultado semelhante ao encontrado por Andrade et al. (1996) e Venturi \& Paulilo (1998), em condições de luz e nutrição de plantas diferentes das deste estudo. Isto parece indicar que enquanto há reservas nas sementes, o desenvolvimento da plântula independe das condições de luz e nutrição dadas e o estádio alcançado ao fim do esgotamento das reservas é o de a planta apresentar segunda folha palmada expandida.

Estes resultados são apoiados por Silva Matos \& Watkinson (1998), que observaram a grande mortalidade de plântulas de Euterpe edulis em campo por volta do surgimento da terceira folha palmada, etapa do desenvolvimento em que a plântula, de acordo com os resultados aqui encontrados, passaria a sofrer influência do ambiente. $\mathrm{O}$ ambiente de sub-bosque, onde as plântulas de E. edulis podem ser encontradas, chega a receber apenas $2 \%$ da radiação solar incidente (Januário et al. 1992), o que poderia limitar o crescimento e a sobrevivência das plântulas.

\section{Efeito da luz e nutrição no crescimento de plantas}

$\mathrm{O}$ crescimento das plantas foi favorecido pela adubação sob maior quantidade de luz (50\%), mostrando interação entre luz e nutrientes apenas quando há nível mais elevado de luz. Este tipo de interação também foi encontrado para E. edulis por Illenseer \& Paulilo (2002), trabalhando com o efeito da variação de nitrogênio e fósforo em diferentes intensidades de luz no crescimento de plantas jovens desta espécie. A interação entre alta nutrição mineral e alta intensidade de luz também foi encontrada em outras espécies florestais por Elliot \& White (1994), Minolta \& Pinzauti (1996), Gunatilleke et al. (1997) e Bungard et al. (2000), considerando os autores que esta resposta é vantajosa na competição entre espécies quando há, por algum motivo, uma abertura no dossel da floresta, possibilitando o aumento de luz.

Em baixa nutrição, as plantas foram prejudicadas mais cedo quando em alta intensidade luminosa do que quando em baixa intensidade luminosa, provavelmente pelo crescimento mais acelerado, utilizando os recursos nutricionais do substrato mais rapidamente, como observado em outras espécies (Chapin et al. 1987). Desta forma, em condições naturais, é possível que a sobrevivência de plantas jovens de E. edulis seja mais baixa em locais ensolarados com baixa disponibilidade de nutrientes do que nos pouco férteis, mas sombreados. Entretanto, estas condições ambientais, a julgar pelos resultados encontrados no presente trabalho, não se fariam sentir nos primeiros meses de crescimento, mas sim em plantas próximas ao primeiro ano de vida.

Em termos de sobrevivência de plantas, sob a baixa intensidade de luz, em alta ou baixa disponibilidade de nutrientes, não foi observado declínio de peso de matéria seca das plantas. Isto poderia indicar que ambientes mais sombreados, a possibilidade de sobrevivência de plantas, embora o crescimento fosse mais lento, seria maior que em ambientes pouco férteis e bastante iluminados.

Analisando o efeito dos tratamentos, tem-se que a taxa de crescimento relativo em termos de peso de matéria seca de plantas, TCR, é dependente da fotossíntese líquida (TAL) e da proporção de área fotossintetizante, RAF, de maneira que o aumento da TAL ou RAF leva a um aumento da TRC (Hunt 1982). Em vista disto, observando-se o efeito da alta e baixa intensidade de luz no crescimento de plantas entre 225 e 405 DAS, período em que as respostas foram mais evidentes, tem-se que, em alta nutrição, a TCR em baixa e alta intensidade de luz foram semelhantes. Analisando em cada caso os valores da RAF no período, tem-se que em alta luz a TCR foi influenciada pela TAL, já que a RAF apresentou menor valor que em baixa intensidade de luz, e, em baixa luz a RAF influenciou a TCR, pois o valor da RAF foi alto. Na ausência de nutrientes, a TCR foi mais alta em baixa intensidade de luz, e, neste caso, tem-se o valor da RAF influenciando a TCR, já que foi mais alto em plantas mais sombreadas.

Observou-se pelos resultados que a taxa de crescimento relativo, em termos de peso de matéria seca, das plantas de E. edulis, foi de $0,016 \mathrm{mg} \mathrm{d}^{-1} \mathrm{em}$ seu valor mais alto. Este valor é inferior ao encontrado para outras espécies da Floresta Atlântica, crescidas em condições similares e de idade similar, como Cecropia glazioui Sneth., com TCR de 0,035 mg d ${ }^{-1}$ (Duz et al. 2004), Tabebuia avellanedae Lorentz ex Griseb., com TCR de 0,040 $\mathrm{mg} \mathrm{d}^{-1}$ (Moratelli et al. 2007), Colubrina glandulosa Perk. e Peltophorum dubium (Spreng) Taub, com valor de TCR ao redor de 0,60 mg.d $\mathrm{d}^{-1}$ (Caus \& Paulilo 2000). Estes dados confirmam os de Yamazoe (1973), os quais indicam lento crescimento para E. edulis nos estádios iniciais de crescimento e os de Piña-Rodrigues et al. (1990) que relatam crescimento mais lento de espécies que se estabelecem mais tarde na sucessão florestal, como é o caso de E. edulis (Klein 1980) em relação a espécies de sucessão inicial, como é o caso das espécies citadas acima. 
Os dados para crescimento de plantas em substrato bem irrigado e deficiente em água mostraram que o teor de água do substrato não alterou o peso de matéria seca de raízes ou de parte aérea da planta. Esta resposta à diminuição de água não era esperada face aos vários resultados de campo com a espécie, os quais têm relacionado a ocorrência de E. edulis a elevado teor de água no solo (Mattos \& Mattos 1972; Bovi 1987; Nogueira Junior et al. 2003). Os estudos em condições controladas nem sempre exprimem o observado em campo, pois em campo há a ação de vários outros processos sobre os quais a água poderia agir como na decomposição da serapilheira (Reissmann et al. 1990), ou no favorecimento da germinação (Nazário \& Ferreira, 2010), o que poderia favorecer a ocorrência de $E$. edulis em locais úmidos. Estudos mais detalhados, entretanto, são necessários para identificar a resposta de crescimento inicial de plantas de E. edulis à variação na disponibilidade de água no solo.

\section{Referências}

Andrade, A.C.S.; Venturi, S. \& Paulilo, M.T.S. 1996. Efeito do tamanho da semente de Euterpe edulis Mart. sobre a germinação e crescimento inicial. Revista Brasileira de Sementes 18: 150-157.

Banzato, D.A. \& Kronka, S.N. 1989. Experimentação agrícola. FUNEP, Jaboticabal. 247p.

Bokhari U.G. \& Trent, J.D. 1985. Proline concentrations in water stressed grasses. Journal of Range Management 38: 37-38.

Bovi, M.L.A.; Godoy, Jr. G. \& Saes, L.A. 1987. Híbridos interespecíficos de palmiteiro (E. oleraceae x $E$. edulis). Bragantia 46: 343-363.

Bungard, R.A.; Press, M.C. \& Scholes, J.D. 2000. The influence of nitrogen on rain forest dipterocarp seedlings exposed to a large increase in irradiance. Plant Cell and Environment 23: 1183-1194.

Caus, C. \& Paulilo, M.T.S. 2000. Influência na quantidade de luz no crescimento inicial de duas espécies arbóreas da Mata Atlântica. Insula 29: 107-115.

Chapin, F.S.; Bloom, A.J.; Field, C.B. \& Waring, R.H. 1987. Plant responses to multiple environmental factors. BioSience 37: 49-57.

Clement, C.R. 2000. Prefácio. In: Reis, M.S. \& Reis, A. (eds.). Euterpe edulis Martius (Palmiteiro) biologia, conservação e manejo. Herbário Barbosa Rodrigues, Itajaí. Pp. v-vi.

Conte, R.; Reis, M.S.; Reis, A.; Mantovani, A.; Mariot, A.; Fantini, A.C. \& Nodari, R.O. 2000. Dinâmica da regeneração natural de Euterpe edulis. In: Reis, M.S. \& Reis, A. (eds.). Euterpe edulis Martius (Palmiteiro) biologia, conservação e manejo. Herbário Barbosa Rodrigues, Itajaí. Pp. 106-130.
Duz, S.R.; Siminski, A.; Santos \& M. \& Paulilo, M.T.S. 2004. Crescimento de três espécies arbóreas da Floresta Atlântica em resposta a variação na quantidade de luz. Revista Brasileira de Botânica 27: 587-596.

Elliot, K. \& White, A.S. 1994. Effects of light, nitrogen and phosphorus on red pine seedling growth and nutrient use efficiency. Forest Science 40: 47-58.

Fetene, M. \& Feleke, Y. 2001. Growth and photosynthesis of seedlings of four tree species from a dry tropical afromontane forest. Journal of Tropical Ecology 17: 269-283.

Gunatilleke, C.V.S.; Gunatilleke, I.A.U.N.; Pereira, G.A.D.; Burslen, D.F.R.P.; Ashton, P.M.S. \& Ashton, P.S. 1997. Responses to nutrient addition among seedlings of eight closely related species of Shorea in Sri Lanka. Journal of Ecology 85: 301-311.

Haig, D. \& Westoby, M. 1991. Seed size, pollination costs and angiosperm success. Evolutionary Ecology 5: 231-247.

Houter, N. \& Steege, H. 2000. The importance of seed mass and canopy openness for the early growth responses of tree seedlings of eight tropical rain forest species. In: Rose, S. (ed.). Seeds, seedlings and gaps - size matters: a study in the tropical rain forest of Guyana. Georgetown, Tropenbos-Guyana Series 9. Pp 19-39.

Hunt, R. 1982. Plant growth curves: the functional approach to plant growth analysis. Edward Arnold Ltd., London. 248p.

Illenseer, R. \& Paulilo, M.T.S. 2002. Crescimento e eficiência na utilização de nutrientes em plantas jovens de Euterpe edulis Mart. sob dois níveis de irradiância, nitrogênio e fósforo. Acta Botanica Brasilica 16: 385-394.

Januário, M.; Viswanadham, Y. \& Senna, R.C. 1992. Radiação solar total dentro e fora da floresta tropical úmida de terra firme. (Tucurí, Pará). Acta Amazonica 22: 335-340.

Klein, R.M. 1980. Ecologia da flora e vegetação do Vale do Itajaí. Sellowia 32: 165-389.

Mattos, M.D.L. \& Mattos, C.C.L.V. 1976. Palmito Juçara - Euterpe edulis Mart (Palmae) - uma espécie a plantar, manejar e proteger. Brasil Florestal 7: 9-20.

Minolta, G. \& Pinzauti, S. 1996. Effects of light and soil fertility on growth, leaf chlorophyll content and nutrient use efficiency of beech (Fagus sylvatica L.) seedlings. Forest Ecology and Management 86: 61-7.

Moratelli, E.M.; Dalla Costa M.; Lovato, P.E.; Santos, M. \& Paulilo, M.T.S. 2007. Efeito da disponibilidade de água e de luz na colonização micorrízica e no crescimento de Tabebuia avellanedae Lorentz ex Griseb. (Bignoniaceae). Revista Árvore 31: 555-566.

Nazário, P. \& Ferreira, S.A.N. 2010. Emergência de plântulas de Astrocaryum aculeatum G. May. em função da temperatura e do período de embebição das sementes. Acta Amazonica 40: 165-170. 
Nakazono, E.M.; Costa, M.C.; Futatsugi, K. \& Paulilo. M.T.S. 2001. Crescimento inicial de Euterpe edulis Mart. Em diferentes regimes de luz. Revista Brasileira de Botânica 24: 173-179.

Nogueira Junior, L.R.; Fisch, S.T.V.\& Ballestero, S.D. 2003. Influência da umidade do solo no desenvolvimento inicial de plantas do palmiteiro Euterpe edulis Mart. em floresta nativa. Revista de Biociências 9: 7-13.

Pinã-Rodrigues, F.C.M.; Costa, L.G.S. \& Reis, A. 1990. Estratégia de estabilidade de espécies arbóreas e manejo de florestas tropicais. Anais do $6^{\circ}$ Congresso Florestal Brasileiro, Campos do Jordão. Pp. 676-684.

Reis, M.S.; Fantini, A.C.; Nodari, R.O; Reis, A.;Guerra, M.P. \& Mantovani, A. 2000. Management and conservation of natural populations in Atlantic Rain Forest: The case study of palm heart (Euterpe edulis Martius). Biotropica 32: 894-902.
Reissmann, C.B.; Santos Filho, A. \& Rocha, H.O. 1990. Composição química foliar do palmito (Euterpe edulis Mart.) em quatro sítios distintos da Mata Atlântica do Paraná. Anais do $6^{\circ}$ Congresso Florestal Brasileiro, Campos de Jordão. Pp. 662-663.

Silva Matos, D.M. \& Watkinson, A.R. 1998. The fecundity, seed and seedlings ecology of the edible palm Euterpe edulis in southeastern Brazil. Biotropica 30: 595-603.

Venturi, S. \& Paulilo, M.T.S. 1998. Esgotamento nas reservas da semente de Euterpe edulis Mart. e efeito da nutrição mineral nas plântulas. Acta Botanica Brasilica 12: 215-220.

Yamazoe, G. 1973. Observações preliminares sobre a altura de Euterpe edulis Mart. Boletim Técnico do Instituto Florestal 6: 17-22. 